\title{
A UTILIZAÇÃO DO FILME "DERSU UZALA" NA FORMAÇÃO DE PROFESSORES PARA A CONSTRUÇÃO DE UMA VISÃO CRÍTICA DA EDUCAÇÃO AMBIENTAL
}

\section{Lucas Aníbal Faria Seabra ${ }^{1}$}

\section{Laise Vieira Gonçalves ${ }^{2}$}

\section{Antonio Fernandes Nascimento Junior ${ }^{3}$}

RESUMO: A necessidade de formação de professoras na perspectiva da Educação Ambiental Crítica (EAC) tem sido relevante uma vez que esta apresenta uma visão mais crítica das questões ambientais e sua relação com as questões sociais. Neste sentido realizou-se um minicurso de EAC pelo Programa Institucional de Bolsa de Iniciação a Docência (PIBID) da Biologia da Universidade Federal de Lavras (UFLA) para licenciandos do curso de Ciências Biológicas desta universidade. Este teve como objetivo aproximar os licenciandos da concepção da EAC, através da utilização de um filme. O minicurso contou com a participação de 18 licenciandos e se constituiu em dois momentos. No primeiro, foi exibido o filme japonês "Dersu Uzala" (1975), dirigido por Akira Kurosawa. Num segundo momento, iniciou-se uma discussão sobre as perspectivas teóricas da Educação Ambiental Conservacionista e da EAC. Em seguida, a problematização construída durante a discussão do filme esteve relacionado às cenas do mesmo. Foi trazida uma discussão sobre o consumismo, onde os participantes citavam e

\footnotetext{
${ }^{1}$ Graduando em Licenciatura em Ciências Biológicas, Universidade Federal de Lavras lucaspta1992@hotmail.com

${ }^{2}$ Graduada em Licenciatura em Ciências Biológicas, Universidade Federal de Lavras laiseokda@hotmail.com

${ }^{3}$ Professor Adjunto do Departamento de Biologia da Universidade Federal de Lavras toni nascimento@yahoo.com.br
} 
reconheciam esse problema no cotidiano e, consequentemente, relacionava-os ao atual modelo econômico. Além disso, relataram como a mídia influencia nas ações dos indivíduos nesta "sociedade do consumo". Também foi discutido a importancia da EAC estar presente no ambiente escolar. E, para tal, é fundamental que esta faça parte dos processos de formação de professores. Assim, a utilização do filme "Deru Uzala" se mostrou uma prática potencializadora na construção de aspectos relacionados a EAC possibilitando sua inserção na formação de professores e, posteriormente, no ambiente escolar.

Palavras Chave: Educação Ambiental Crítica. Formação de professores. Cinema.

\section{INTRODUÇÃO}

As atividades pedagógicas da Educação Ambiental Crítica (EAC) são desenvolvidas no sentido de promover a formação humana para a transformação da relação sociedade e natureza contrapondo-se aquela característica do sistema capitalista vigente. Uma de suas principais finalidades, portanto, é a busca pela construção de uma sociedade que, ao contrário da atual, seja pautada no equilíbrio ecológico, na valorização cultural, na justiça social e na atuação política de todos (LAYRARGUES, 2006).

A forma com que a Educação Ambiental é proposta nos Parâmetros Curriculares Nacionais (PCNs) é feita por meio do tema transversal Meio Ambiente. Assim, ela deve permear todas as disciplinas proporcionando um grande leque de possibilidades de trabalhos educativos envolvendo o tema meio ambiente. Porém, como lembra TozzoniReis (2001) a Educação Ambiental exige duas dimensões para análise, não estando apenas restrita ao conteúdo meio ambiente, sendo elas: a dimensão epistemológica e a dimensão pedagógica. Isso porque exige reflexões acerca da problemática ambiental e da especificidade da Educação.

Do ponto de vista da problemática ambiental é necessário que seja feita uma discussão mais crítica sobre ela e realizar a aproximação destas discussões no ambiente escolar. Como apontado por Guimarães (2004), o modelo tradicional de ensino de 
transmissão de conteúdos ainda é muito forte e certamente mais profundamente inserido no ideário e nas atividades pedagógicas dos professores que se debruçam sobre a Educação Ambiental. Com isso, transformar a teoria e os discursos em ações pedagógicas crítico-reflexivas ainda é um grande obstáculo. Para tanto, a formação de professores exerce um papel ativo, pois de acordo com Penteado (2007), compreender as questões ambientais, para além de suas dimensões biológicas, químicas e físicas, considerando as implicações sócio-políticas e culturais exige a formação de uma "consciência ambiental" e a formação para o pleno exercício da cidadania.

Nesse sentido atividades que proporcionam uma formação embasada em situações atuais que permeiam não só o âmbito escolar são de extrema importância para um despertar de uma consciência critica que leve ao sujeito uma reflexão contínua e transformadora sobre o que lhe é imposto.Para que isso não fique preso somente em programas que buscam caminhos para chegar as melhorias do sistema educacional com futuros docentes, a participação voluntária, material de apoio, coerência , integração conteúdo-metodologia juntamente com a participação de grupos de professores deve fazer parte do cotidiano dos mesmos atuantes para que participem deste processo de formação continuada e possam contribuir cada vez mais para o despertar de uma consciência transformadora do aluno.

Com esta preocupação, foi realizado um minicurso de Educação Ambiental Crítica pelo Programa Institucional de Bolsa de Iniciação a Docência (PIBID) da Biologia da Universidade Federal de Lavras (UFLA) para licenciandos do curso de Ciências Biológicas desta universidade com o objetivo de aproximá-los desta discussão. Sendo que este processo é relatado no presente trabalho.

O principal recurso didático utilizado no minicurso foi um filme. Esta utilização procurou valorizar as potencialidades educativas das tecnologias de informação e comunicação, buscando considerar um elemento presente na sociedade dando-Ihe uma outra finalidade. Além disso, o trabalho com tal recurso pode fomentar uma maior relação entre a escola e a sociedade, aspecto que, segundo Borges e Lima (2007) é fundamental pois o acentuado desenvolvimento científico e tecnológico influencia o conjunto da sociedade, demandando da escola a necessidade de criar um ambiente que auxilie o 
aluno a lidar com a massa de informações que recebe, selecionando-a, hierarquizando-a e manifestando-se criticamente perante ela.

Ainda como afirmam Ferraz e Cavalcanti (2006), a exibição e discussão de um filme, é um elemento eficaz na construção de conhecimento e enriquecedor de experiências, pois traz para o aluno a visualização da imagem e através desta, outros prismas enriquecedores. Dentre as possibilidades, há o exercício de identificação da linguagem que os personagens utilizam no tempo histórico representado, bem como do figurino, que revelam uma época, uma tendência ou uma cultura. Também, expressam formações sociais, políticas e religiosas, paisagens geográficas e históricas. Em todos esses aspectos, o filme é revelador e caminho facilitador para o aluno no processo de construção e reconstrução de conhecimentos sobre a realidade.

\section{DESENVOLVIMENTO}

\subsection{METODOLOGIA}

A atividade foi desenvolvida no Museu de História Natural (MHN) da UFLA durante a XI Semana Nacional de Museus. Esta foi organizada pelos bolsistas do Programa Institucional de Bolsas de Iniciação á Docência (PIBID) de biologia desta instituição. minicurso contou com a participação de 18 licenciandos e constituiu em dois momentos. No primeiro, foi exibido o filme japonês “Dersu Uzala” (1975), dirigido por Akira Kurosawa com duração de 1h 41 minutos. A história do filme se passa no ano de 1910 na Sibéria. Relata a história de um capitão do exército russo (líder de uma expedição de levantamento topográfico na Sibéria), que se encontra com um caçador chamado Goldi (Dersu Uzala), este passa a orientar o oficial pela floresta, dando início a uma forte amizade.

Dersu é um homem sábio que possui uma relação muito especial com a natureza. Ele é um exemplo de humildade e sabedoria. O filme mostra de maneira poética e sensível as diferentes manifestações culturais entre ele e o oficial/pesquisador russo. 
Durante essa expedição Dersu e toda a companhia passa por muitos desafios e aprendizados. A amizade entre o oficial e Dersu fica tão forte que o explorador decide levar o caçador para a cidade cujos costumes se confrontam, de forma drástica, com o modo de vida burocrático da cidade, fazendo-o questionar diversos padrões da sociedade urbana. O filme se destaca também pelas impressionantes paisagens naturais da Sibéria, registradas em belas filmagens.

Num segundo momento, após o filme, iniciou-se uma discussão que procurou contrapor as perspectivas teóricas da Educação Ambiental Conservacionista e da EAC, dando um enfoque maior nesta última. Os prelecionistas procuravam valorizar, a todo momento, os conceitos trazidos pelos participantes sobre a EA e uma possível reconstrução de conceitos sobre o amplo tema. A argumentação foi no sentido de destacar a existência de diferentes concepções teóricas de Educação ambiental, ressaltando a necessidade de um posicionamento pelos indivíduos ao considerar as diversas realidades manifestadas mundialmente sobre a EA. Toda a atividade foi filmada e analisada a fim de avaliar a prática desenvolvida.

\subsection{RESULTADOS E DISCUSSÃO}

A problematização construída durante a discussão do filme esteve, em primeiro momento, relacionado às cenas do mesmo, as quais foram retomadas pelos participantes. Estas cenas encontram-se descritas abaixo:

2.2.1 Falas dos participantes referente às cenas do filme e sobre as discussões mediadas pelos prelecionistas.

P1 - "Eu gostei da despedida e do encontro deles (Dersu e o Capitão)"

P2 - "Eu gostei da parte que o chinês velho esta lá sentado em frente a cabana"

P3 - "Achei interessante a hora que ele (Dersu) mata o tigre e teve um choque momentâneo, a crença né, até ele mesmo narra e explica a crença dele. E a transição dele (Dersu) das colinas para a cidade, a fase de adaptação". 
P4 - "Legal também quando ele (Dersu) se depara com as tecnologias e hábitos da cidade e fala: Porque que aqui na cidade a gente não pode dormir ao ar livre? Querendo entender porque que aqui não pode fazer certas coisas".

P5 - "Achei a cena que eles (Dersu e Capitão) cortam o mato para fazer a cabana, muito linda".

P6 - "Interessante que o Capitão nem sabia pra que era o mato e de desespero da nefasta ele fez o que Dersu mandava".

P3 - "Também gostei muito desta cena e da atitude deles durante a nefasta em busca da sobrevivência".

P7 - "Uma parte que eu gostei foi da ingenuidade dele (Dersu), onde ele dá o dinheiro para o comerciante e o comerciante foge. E ele fica achando um absurdo, como se isso não pudesse acontecer".

P2 - "Interessante como ele (Dersu) era tão esperto para as coisas que ele está acostumado, mas tão ingênuo para outras coisas".

P1 - "Gostei da parte que ele (Dersu) fala das armadilhas, onde ele fala para tirarem as armadilhas, questionando pra que matarem os animais em vão e propõe destruir tudo".

P8 - "O que eu achei muito interessante é que a única coisa que ele (Dersu) tinha para fazer na cidade era observar o fogo na lareira. Era a única ponte que ele tinha com o ambiente que vivia antes".

P3 - "Nos momentos após Dersu matar o tigre ele evita fazer certas coisas, passa a fazer as coisas diferente e fica com esta ideia que se eu fizer vai voltar pra mim".

P9 - "Tem ma cena que ele (Dersu) fala: Vocês estão olhando igual criança. Vocês olham, mas não enxergam.

Prelecionista 1 - "A EAC e este modelo econômico são incompatíveis. Então é muito difícil você ter um pensamento crítico se você quiser continuar seguindo este modelo econômico vigente hoje, pois ele te leva a fazer o contrário do que a EAC propõe. E, aí entra o consumismo, o qual é importante para manter este modelo.

P1 - "Um dos principais princípios do capitalismo é o individualismo, sendo uma das questões que continuam colaborando com a questão do consumo. E ainda trabalha com uma ideia finalista: Você faz isto para acontecer aquilo, você não entende o caminho nem o porque daquilo."

Prelecionista 2- "No filme agente viu a diferença de comportamento dos dois (Dersu e Capitão). Para Dersu, há algumas coisas que a gente faz que é impensável mas que nós não damos o valor necessário ás coisas".

P10 - "Eu estava lendo os Anais dos ENEBios para um trabalho que eu estou escrevendo e uma das categorias é justamente esta: As concepções que os professores têm sobre educação ambiental. E deu para perceber que é principalmente, na perspectiva conservacionista e, que eles não tiveram uma formação voltada para a perspectiva crítica.

P1 - "Ai eu questiono: Se você não é formado, como você vai formar nesta perspectiva crítica? P11 - "Também temos outro problema muito grande que é a mídia. Ela está tão cheia de informação que 
tanto o professor usa, quanto o aluno usa. Não há uma seleção adequada".

P6 - "E percebemos o quanto que esta (a mídia) esta contribuindo para a difusão do consumismo, cada vez mais frequente".

P8 - "Eu vejo que está gerando uma falsa expectativa de que está sendo cumprida a real finalidade. Meio que tapar o sol com a peneira: você esta conservando e vai dar tudo certo.

P9 - "É a mesma fala de quem diz: 'Ah, eu to reciclando o meu lixo, to fazendo a minha parte e vou salvar o planeta"'.

\subsubsection{Um pouco de discussão}

Alguns participantes retomaram as cenas onde Dersu demonstra, continuamente, um conhecimento e uma valorização do ambiente. Uma das cenas retomadas é aquela em que Dersu e o Capitão se encontram diante de uma nefasta. Dersu determina, rapidamente, que eles cortassem as plantas herbáceas que estavam ao redor. Estas, posteriormente, seriam utilizadas para a construção de uma cabana servindo de abrigo durante a tempestade de neve, sendo fundamental para a sobrevivência de ambos.

Também foi trazida, pelos prelecionistas e participantes, uma discussão sobre o consumismo, estreitamente relacionado ao atual modelo econômico abordando também a influência da mídia nas ações dos indivíduos nesta "sociedade do consumo". Houve relação neste momento nas cenas em que Dersu é direcionado para o meio urbano e se depara com várias tecnologias e leis que regem aquele local, mostrando a manipulação de uma sociedade não conhecida por ele. Neste momento a discussão foi aprofundada, destacando a dificuldade de diálogo entre o que a EAC se propõe e os valores e ações característicos do capitalismo, sendo que nesta perspectiva teórica este sistema é o principal causador das problemáticas ambientais.

Ressaltou-se a questão da Educação Ambiental Crítica como uma perspectiva que critica a ordem deste sistema, propondo-se à transformação social, sendo que esta perspectiva, para atingir o ambiente escolar, deve fazer parte dos processos de formação de professores. Para alguns professores, esse processo de reflexão sobre a práxis exige uma transformação pessoal e uma reflexão sobre a própria imagem e auto-imagem profissional (ARROYO, 2000). Dessa forma, o professor é "indiretamente formado" por 
referenciais externos à escola, fato que pode contribuir com a fragilização desse processo formativo (GUIMARÃES, 2004).

É necessário que se forme uma consciência transformadora e crítica sobre o que nos é imposto para que se possa motivar e construir a mesma nos alunos, onde é necessário quebrar uma grande barreira que é construída, a todo momento, pelo sistema econômico em qual estamos inseridos. Em consonância com Santos (2000) conceber uma globalização contra-hegemônica é reinventar a emancipação a partir de alianças que lutem contra a exclusão, a exploração e a opressão produzidas pela globalização neoliberal. Para ele, é preciso construir espaços de participação democrática, de conhecimentos emancipatórios, de novas solidariedades, e novos modos de produção e convivência cultural a fim de criar alternativas à racionalidade do capitalismo global.

\section{CONCLUSÃO}

Assim, pode-se perceber que a utilização do filme "Dersu Uzala" e as discussões feitas referentes ao mesmo durante o minicurso, inseridas em um contexto históricosocial, favoreceu a construção de aspectos relacionados a EAC possibilitando sua inserção na formação de professores e, posteriormente, no ambiente escolar se mostrando uma prática potencializadora.

\section{REFERÊNCIAS}

ARROYO, M. Ofício de mestre: imagens e auto-imagens. Petrópolis, RJ: Vozes, 2000.

BORGES mas LIMA. Tendências contemporâneas do ensino de biologia no brasil. v. 6, № 1, 2007.

FERRAZ mas CAVALCANTI. História de cinema: luz, câmara, transposição didática: Historia e Ensino. Londrina, v.12, ago. 2006.

GUIMARÃES, M. A formação de educadores ambientais. Campinas: Papirus, 2004. 
LAYRARGUES, P.P. Muito além da natureza: educação ambiental e reprodução social. In: LOUREIRO, B.F.B.; LAYRARGUES. P.P.; CASTRO, R.S. (Org.). Pensamento complexo, dialética e educação ambiental. São Paulo: Cortez, 72-103p, 2006.

PENTEADO, H. Meio ambiente e formação de professores. 6ª edição. São Paulo: Cortez, 2007.

SANTOS, B. de S. A crítica da razão indolente: contra o desperdício da experiência. São Paulo: Cortez, 2000.

TOZZONI-REIS, M. F. C. Educação ambiental: referências teóricas no ensino superior. Interface_Comunic, Saúde, Educ, v.5, n.9, p.33-50, 2001. 